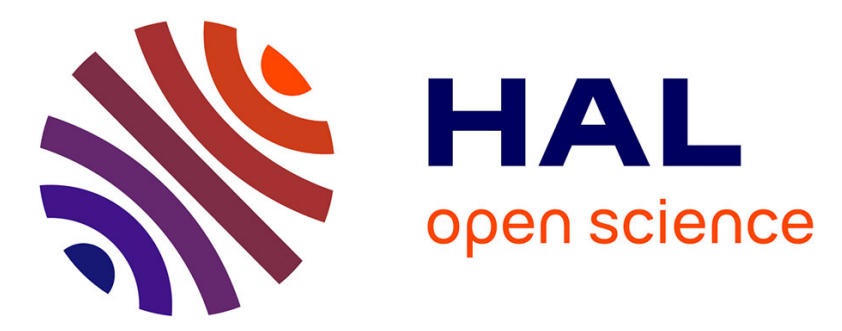

\title{
Properties evolution of flax/epoxy composites under fatigue loading
}

\author{
Shaoxiong Liang, Papa-Birame Gning, Laurent Guillaumat
}

\section{To cite this version:}

Shaoxiong Liang, Papa-Birame Gning, Laurent Guillaumat. Properties evolution of flax/epoxy composites under fatigue loading. International Journal of Fatigue, 2014, 63, pp.36-45. 10.1016/j.ijfatigue.2014.01.003 . hal-01067057

\section{HAL Id: hal-01067057 https://hal.science/hal-01067057}

Submitted on 22 Sep 2014

HAL is a multi-disciplinary open access archive for the deposit and dissemination of scientific research documents, whether they are published or not. The documents may come from teaching and research institutions in France or abroad, or from public or private research centers.
L'archive ouverte pluridisciplinaire HAL, est destinée au dépôt et à la diffusion de documents scientifiques de niveau recherche, publiés ou non, émanant des établissements d'enseignement et de recherche français ou étrangers, des laboratoires publics ou privés. 


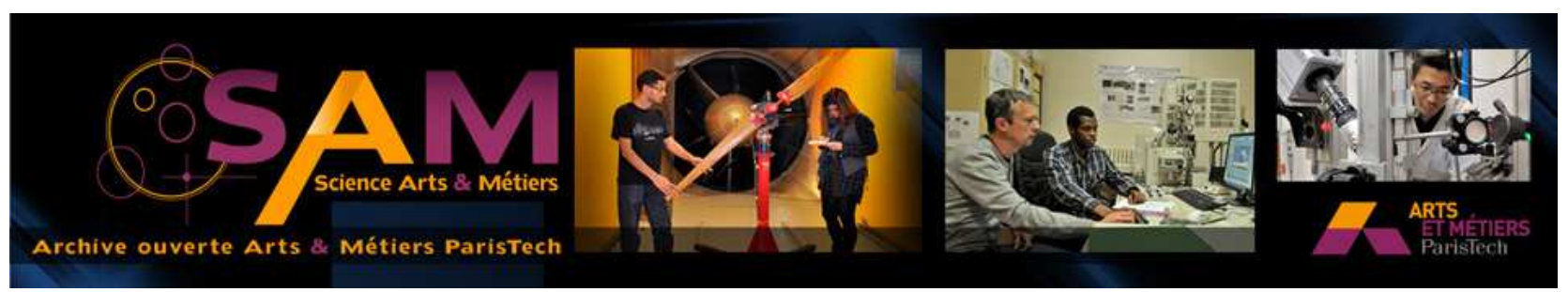

Science Arts \& Métiers (SAM)

is an open access repository that collects the work of Arts et Métiers ParisTech researchers and makes it freely available over the web where possible.

This is an author-deposited version published in: http://sam.ensam.eu

Handle ID: .http://hdl.handle.net/10985/8601

\section{To cite this version :}

Shaoxiong LIANG, Papa-Birame GNING, Laurent GUILLAUMAT - Properties evolution of flax/epoxy composites under fatigue loading - International Journal of Fatigue - Vol. 63, p.36-45 2014 


\title{
Properties evolution of flax/epoxy composites under fatigue loading
}

\author{
Shaoxiong Liang ${ }^{\mathrm{a}, *}$, Papa-Birame Gning ${ }^{\mathrm{a}}$, Laurent Guillaumat ${ }^{\mathrm{b}}$ \\ a DRIVE-ISAT, Université de Bourgogne, 58027 Nevers Cedex, France \\ ${ }^{\mathrm{b}}$ LAMPA, Arts et Métiers ParisTech, 49100 Angers Cedex, France
}

\section{Keywords:}

Flax fibres

Polymer-matrix composites (PMCs)

Fatigue

Damage mechanics

\begin{abstract}
A B S T R A C T
The tension-tension fatigue behaviour of flax fibre reinforced epoxy matrix composites have been investigated for specimens having $[0]_{12},[90]_{12},[0 / 90]_{3 s}$ and $[ \pm 45]_{3 S}$ lay-ups. The Probabilized Stress-Number of cycles (P-S-N) curves have been determined for each laminate type. The measured stress and strain data allowed to quantify the evolution of the mechanical properties, i.e. stiffness, damping and permanent strain as a function of imposed cycles. Especially, the stiffening phenomenon of flax reinforcements oriented parallel to the loading direction has been confirmed. However, due to the competition between damage development and the fibre stiffening, the increase in the longitudinal Young's modulus was noticed on the composites depending on the ratio of fibres parallel to load direction.
\end{abstract}

\section{Introduction}

Composite materials have good mechanical properties to weight ratio compared to metals. However, the processing of conventional fibres, e.g. glass, carbon, is energy-intensive and there is no efficient recycling process actually easy for glass or carbon fibres reinforced thermoset matrix composites. Therefore, the development of natural fibres as an alternative reinforcement for mass produced composite materials has been recently driven by increasing environmental pressures. The mechanical properties of agro-fibres (wood, cotton [1], hemp [2,3], sisal [4], flax [5,6], etc.) have been studied [7] and flax fibres have exhibited comparable specific properties to glass ones. Consequently, this interest has brought authors to focus on bio-based composites fibre/matrix interface by alkali treatment or addition of coupling agents $[8,9]$. Quasi-static mechanical properties [10], aging [11], the influence of process parameters [12] and impact response [13] are also wildly investigated.

Regarding the fatigue behaviour, Tong and Isaac [14] have compared the fatigue response of hemp fibre mat and $\pm 45^{\circ}$ glass fibre reinforced composites. These authors have reported that hemp fibre reinforced polymer specimens failed without any prior observable effect on the modulus during fatigue cycling. Towo and Ansell [15] have studied the effects of chemical treatments on reinforcements and matrix modification of unidirectional (UD) sisal fibres impregnated with epoxy and polyester matrix. Results have shown that the $\mathrm{NaOH}$ treatment improved slightly the fatigue

\footnotetext{
* Corresponding author. Tel.: +33 3867150 48; fax: +33 386715001 E-mail address: shaoxiong.liang@ensam.eu (S. Liang).
}

resistance. Moreover, the UD sisal/epoxy has exhibited a moderate raise of its initial stiffness under tension-tension fatigue test. Shah et al. [16] have investigated the influence of reinforcement (jute, hemp and flax, glass), stacking sequence and fibre content on the fatigue response of composites. Results have highlighted that the stiffer composite, i.e. UD glass fibre laminate with the highest fibre content loaded along fibre direction, exhibited the best fatigue resistance. In our previous study [17], the fatigue behaviours of flax/epoxy and glass/epoxy with the same stacking sequence and similar fibre volume fractions have been compared. It was shown that both materials have similar fatigue performance for low loading levels, i.e. long term life. It emerged from this review that very few studies have been conducted on flax fibre reinforced composites, especially on the damage evolution. Therefore, the present paper is aimed at the determination of Probabilized Stress-Number of cycles (P-S-N) curves and damage evolution of flax/epoxy composites with $[0]_{12},[90]_{12},[0 / 90]_{35}$ and $[ \pm 45]_{3 S}$ stacking sequences. The permanent strain, energy dissipation, the dynamic modulus and the fatigue modulus as well as the crack density evolution are analyzed and discussed.

\section{Experimental methods}

\subsection{Materials and specimens}

Specimens were fabricated from commercial dry reels of Hermès flax cultivated in northern France. Unidirectional (UD) and non-crimp balanced flax fabrics, with areal weights of $144 \mathrm{~g} / \mathrm{m}^{2}$ and $235 \mathrm{~g} / \mathrm{m}^{2}$, were ordered from CRST, a local textile company. The latter fabric is made of two identical layers of UD 
Table 1

Physical properties and ultimate tensile stresses (UTS) of composites. Standard deviations in brackets.

\begin{tabular}{|c|c|c|c|c|c|c|}
\hline Notation & Stacking sequence & Fabric & $V_{f}(\%)$ & $\rho_{c}\left(\mathrm{~kg} / \mathrm{m}^{3}\right)$ & $t(\mathrm{~mm})$ & UTS (MPa) \\
\hline FE_0 & {$[0]_{12}$} & UD & $43.1(1.5)$ & $1310(10)$ & $2.55(0.12)$ & $318(12)$ \\
\hline FE_90 & {$[90]_{12}$} & & & & & $26.1(0.6)$ \\
\hline FE_090 & {$[0 / 90]_{3 \mathrm{~S}}$} & Non-crimp & $43.7(0.6)$ & $1280(10)$ & $2.18(0.07)$ & $170(20)$ \\
\hline FE_45 & {$[ \pm 45]_{3 S}$} & & & & & $79(7)$ \\
\hline
\end{tabular}

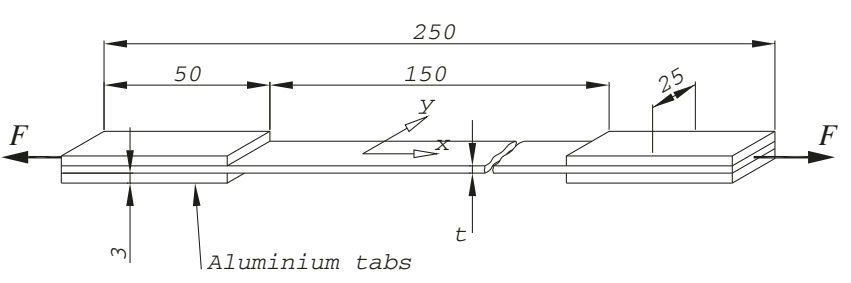

Fig. 1. Geometry of the fatigue specimens. Dimensions in mm. The $x$ and $y$ axis were designated as the longitudinal and transverse in-plane directions respectively.

fibres oriented perpendicularly to one another and stitched together by a cotton thread. Both types of fabrics were used as received, without any further treatment. The matrix used was an epoxy system: SR 8200 resin and SR 8205 hardener, both provided by SICOMIN. Its glass transition temperature was $88^{\circ} \mathrm{C}[12]$ and its density was $1143 \mathrm{~kg} / \mathrm{m}^{3}$ at $20^{\circ} \mathrm{C}$.

After have been cut from the reel, the layers of fibres were impregnated with the liquid matrix and hand stacked in a flat metal mould to ensure a given thickness before curing by thermocompression. Our apparatus consisted of two heated plates. The temperature rate was $2{ }^{\circ} \mathrm{C} / \mathrm{min}$ up to the constant temperature of $60^{\circ} \mathrm{C}$ during $8 \mathrm{~h}$, followed by final air cooling step. A pressure of 7 bars was maintained throughout the curing process. Notation, stacking sequences, fibre volume fraction $\left(V_{f}\right)$, densities $\left(\rho_{c}\right)$ and thicknesses $(t)$ of all specimens are given in Table 1. Fibre fractions of approximately $43 \%$ were measured, on considering the density of flax fibre to be $1500 \mathrm{~kg} / \mathrm{m}^{3}$ [18], for the four types of composites according to ASTM standard [19]. The porosity was measured by optical microscope images and was found in the range of $1-3 \%$.

The geometry of the fatigue specimens, as presented in Fig. 1, was similar to that of quasi-static tensile samples prescribed by ISO 527 standard. Specimens consisted of rectangular coupons of composite with aluminium end tabs glued on. Prior to fatigue testing, the ultimate tensile stresses (UTS) of each type of specimens were determined (Table 1 ) in quasi-static mode according to the ISO 527 standard.

\subsection{Fatigue testing procedures}

The fatigue tests were carried out according to ISO 13003 standard [20]. In order to avoid excessive self-heating (less than $10^{\circ} \mathrm{C}$ ), the loading frequency of $5 \mathrm{~Hz}$ was identified by a Doehlert experimental program [17]. Tension-tension fatigue tests were conducted under load amplitude control mode with a loading ratio of $R=0.1$. For each of the five stress levels ranging from 0.4 to 0.8 UTS, by increments of 0.1 UTS, five replicate tests were performed for all types of specimens. Tests were stopped at failure or after $2 \times 10^{6}$ cycles, whichever came first. Tests were realised on a servo-hydraulic MTS 809 machine with a capability of $100 \mathrm{kN}$, with a Servathin thermal chamber maintaining a constant temperature of $23^{\circ} \mathrm{C}$, without humidity control.

One complete cycle was recorded for every 5-2000 cycles, depending on the loading level and the stacking sequence. For the each recorded loop, 21 pairs of displacement-force data were recorded (every $10 \mathrm{~ms}$ ) in order to have a good enough precision. The displacement sensor of the testing machine had a resolution $(\Delta l)$ of $0.003 \mathrm{~mm}$ corresponding to a strain precision $\left(\Delta l / l_{0}\right)$ of $0.002 \%$ for specimens with a nominal gauge length $\left(l_{0}\right)$ of $150 \mathrm{~mm}$ (Fig. 1). This accuracy of strain data was considered acceptable after comparison with strain gauge measurements presented later. Thus, the strain measurements for the fatigue tests were computed from the ratio of crosshead displacement to the gauge length.

\subsection{Microscope observation}

Fibre fractured edges were examined by Scanning Electron Microscopy (SEM) with a Zeiss Supra 25 microscope, after coating with a thin layer of gold. The crack density evolution for FE_45 and FE_090 specimens were measured by direct observation with an Axiovert optical microscope. Untested samples and fatigue tested samples with different numbers of cycles with a loading level of 0.6 UTS. All samples were sliced and fine polished before observations.

\section{Results and discussion}

\section{1. $P-S-N$ curves}

The average fatigue lives expressed in number of cycles to failure $\left(N_{f}\right)$ and $\log _{10}\left(N_{f}\right)$, with standard deviations in brackets, are listed in Table 2.

The stress/number of cycles measurements are plotted in Fig. 2a-d. Data points with arrow are unbroken samples up to the endurance limit fixed at two million cycles. Modified Wöhler law (Eq. (1)) was used to model specimens life [20].

$\log \left(N_{f}\right)=A-B \cdot \sigma_{x}+C \cdot S$

where $\sigma_{x}$ is the axially maximum loading stress, $A$ and $B$ represent intrinsic parameters of the tested material. $C$ stands for the number of standard deviations $(s)$ corresponding to the specified confidence level [21]. The standard deviation $s$ parameter is considered constant throughout all loading levels for any given type of specimen.

Table 2

Average number of cycles to failure of flax/epoxy specimens as a function of UTS ratio. Standard deviations in brackets.

\begin{tabular}{|c|c|c|c|c|c|}
\hline & 0.8 UTS & 0.7 UTS & 0.6 UTS & 0.5 UTS & 0.4 UTS \\
\hline FE_0 & 924 (669) & 3930 (1810) & $30,380(10,817)$ & $137,349(44,196)$ & $618,124(401,505)$ \\
\hline FE_90 & $563(554)$ & $3938(2264)$ & $32,346(12,297)$ & $404,589(194,035)$ & $>2 \times 10^{6}$ \\
\hline FE_090 & $2735(1878)$ & $18,069(11,414)$ & $100,576(112,561)$ & $269,509(119,184)$ & $1,143,909(627,943)$ \\
\hline FE_45 & 3679 (3637) & $24,409(14,337)$ & $383,972(124,712)$ & $>2 \times 10^{6}$ & $>2 \times 10^{6}$ \\
\hline
\end{tabular}




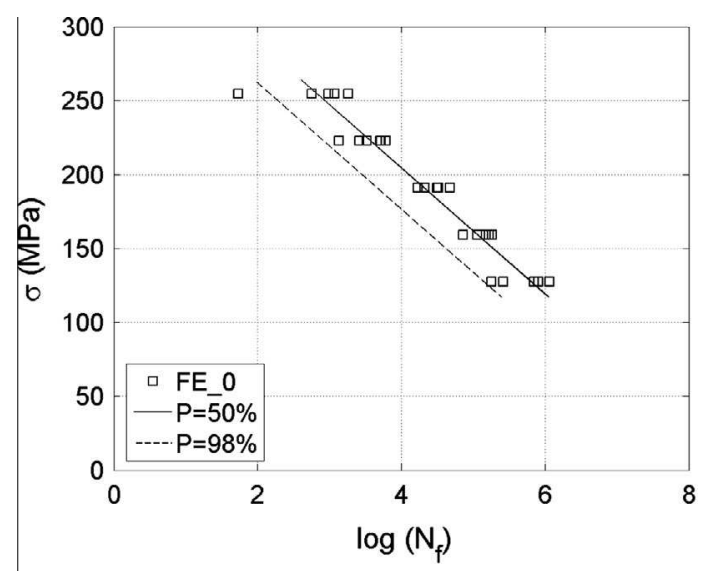

(a)

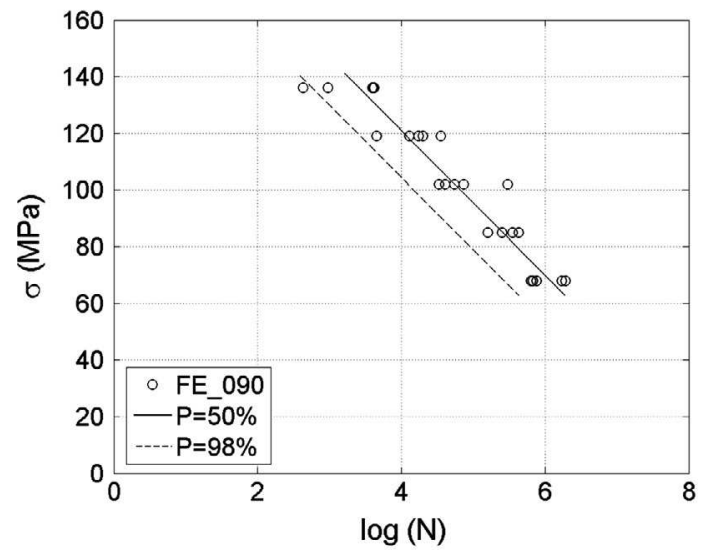

(c)

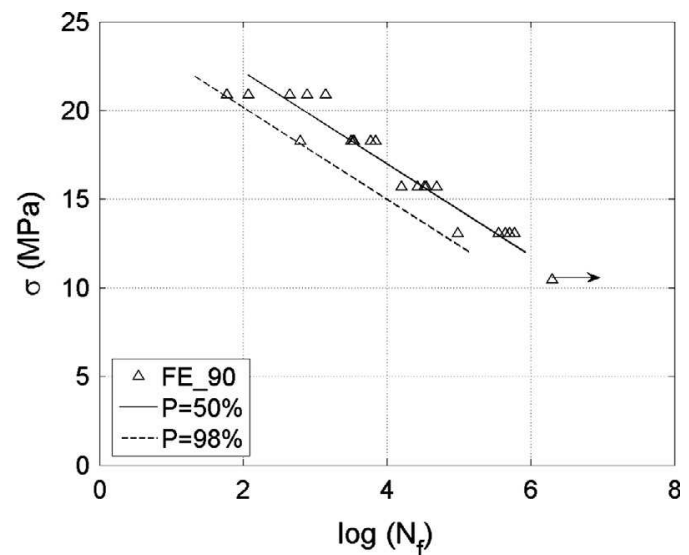

(b)

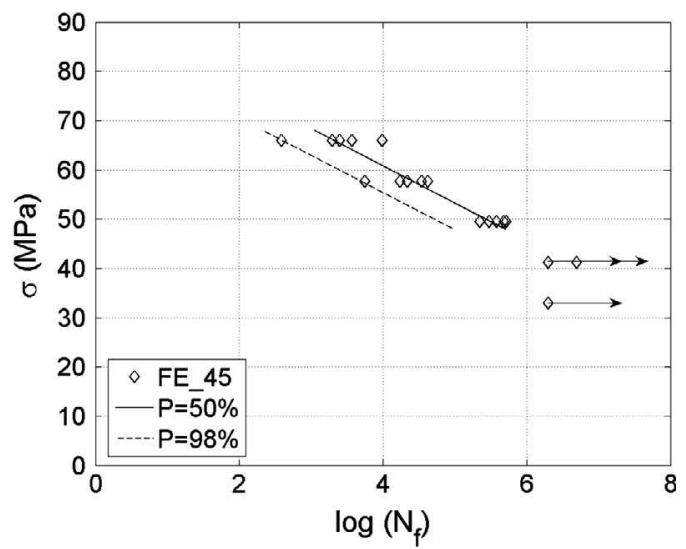

(d)

Fig. 2. Experimental results and P-S-N curves of (a) FE_0, (b) FE_90, (c) FE_090 and (d) FE_45 specimens.

Table 3

Fitted data for Wöhler's law parameters and the linear regression coefficient.

\begin{tabular}{lrlll}
\hline & \multicolumn{1}{l}{$A$} & $B$ & $s$ & $R$ \\
\hline FE_0 & 8.7861 & 0.0234 & 0.3278 & -0.944 \\
FE_90 & 10.5534 & 0.3859 & 0.3863 & -0.954 \\
FE_45 & 12.0941 & 0.2662 & 0.3607 & -0.936 \\
FE_090 & 8.7366 & 0.0392 & 0.3238 & -0.950 \\
\hline
\end{tabular}

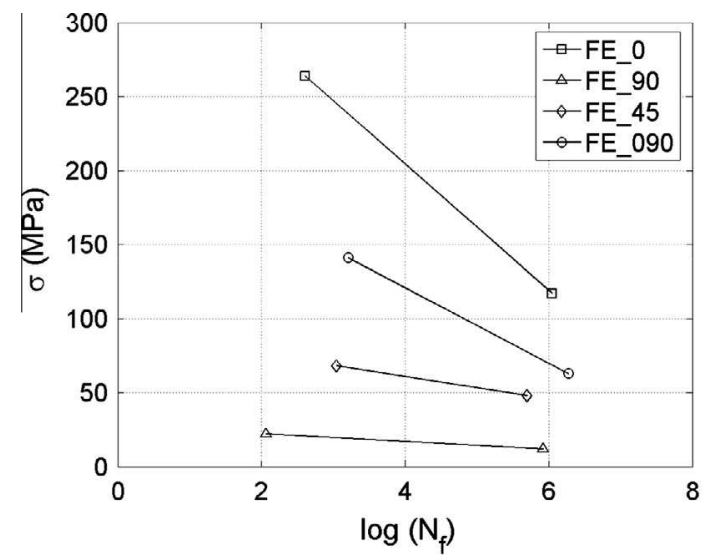

(a)
The identified values for the parameters of Eq. (1) are given in Table 3 and the corresponding curves are plotted in Fig. 2a-d. C equals to 0 and -2 , correspond respectively to Wöhler's curve with $50 \%$ and $98 \%$ of survival probability $(P)$.

Standard deviations for all stacking sequences are all within a narrow range of $0.3238-0.3863$ (Table 3 ). The linear regression coefficient $(R)$ of the Wöhler's curves having $50 \%$ confidence is

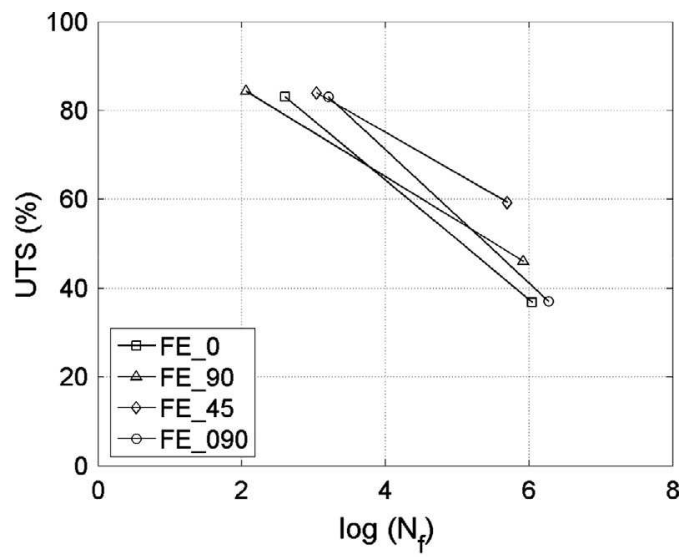

(b)

Fig. 3. Plots of (a) effective stress and (b) normalized to UTS as a function of life cycles. 


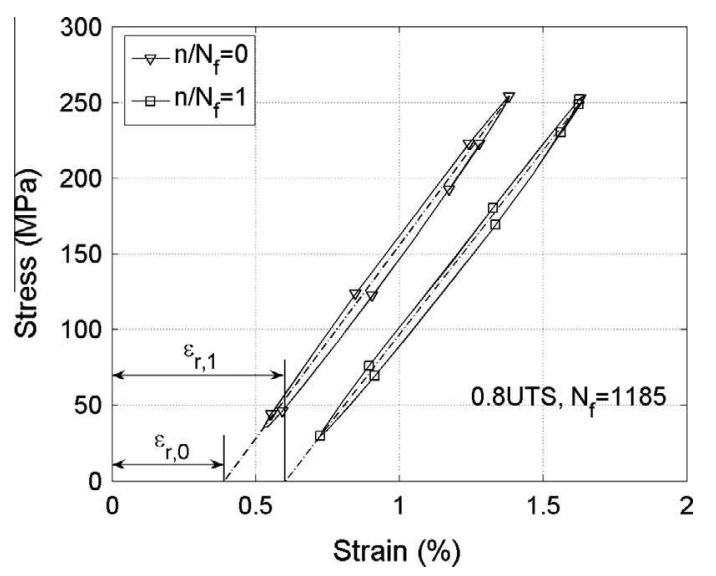

Fig. 4. First and final hysteresis loops of FE_0 specimens tested at 0.8 UTS.

close to 1 for all types of samples, indicating the good fit of the model to experimental data.

The average $\mathrm{S}-\mathrm{N}$ curves $(P=50 \%)$ in terms of effective and relative stresses (referred to the UTS) for all types of specimens, are superimposed in Fig. 3a and b. One can conclude from Fig. 3a that the fatigue resistance of the laminates seems to correlate with their ultimate tensile stress (Table 3), i.e. higher tensile strength leads to higher fatigue resistance. In relative fatigue loading (Fig. 3b), FE_45 seems to have better endurance performance than others. Its endurance limit is 0.5 UTS, while that of FE_90 is 0.4 UTS and lower than 0.4 UTS for FE_0 and FE_090. The slopes of FE_45 and FE_90 are identical because for both stacking sequences, the behaviour is mainly controlled by the matrix. Conversely, FE_0 exhibit a steeper slope, similar to that of FE_090, due to the strong influence of the fibres.

\subsection{Residual strains}

Typical stress-strain hysteresis loops of early $\left(n / N_{f}=0\right)$ and last loading cycles $\left(n / N_{f}=1\right)$ of FE_0 are presented in Fig. 4 . It should be noted that these loops move towards higher strain for constant stress level. This creep-like behaviour is caused by the fatigue loading consisting of a non-zero static load superimposed with sinusoidal variations for a loading ratio of 0.1 [22].

The development of residual strain (permanent strain, $\varepsilon_{r}$ in Fig. 4) is plotted as a function of the life ratio, the number of cycle to the total cycle to failure, for all loading levels (Fig. 5a-d) in order to evaluate the kinetics of creep during lifetime. The scattering bars reveal an acceptable dispersion of data. The permanent strain increased monotonically with the life ratio for any layup and loading level. The results of 0.4 and 0.5 UTS for FE_45 were not plotted since no breakage occurred during these tests.

For a given laminate, the residual strain increases with the imposed load, except for those of FE_90. In this particular case, the range of measured value is small $(0.02-0.11 \%)$, compared to that of FE_0, FE_090 and FE_45 (0.2-1.5\%). Thus, the comparison between loading levels of FE_90 could be disturbed by the

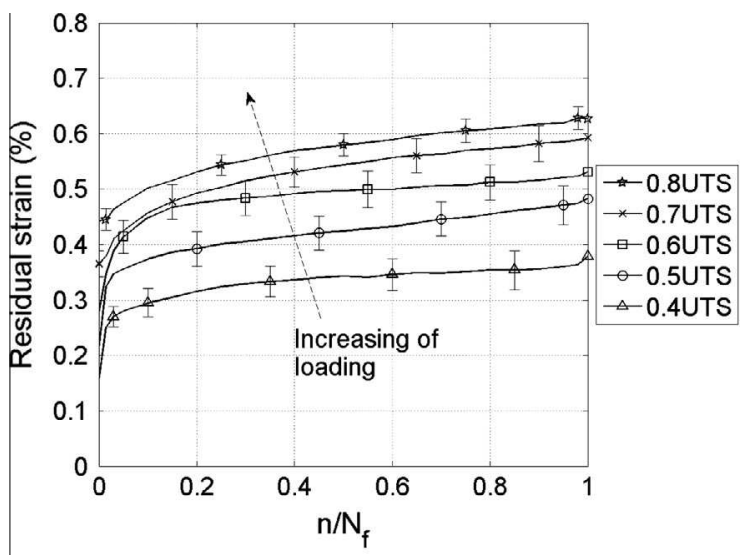

(a)

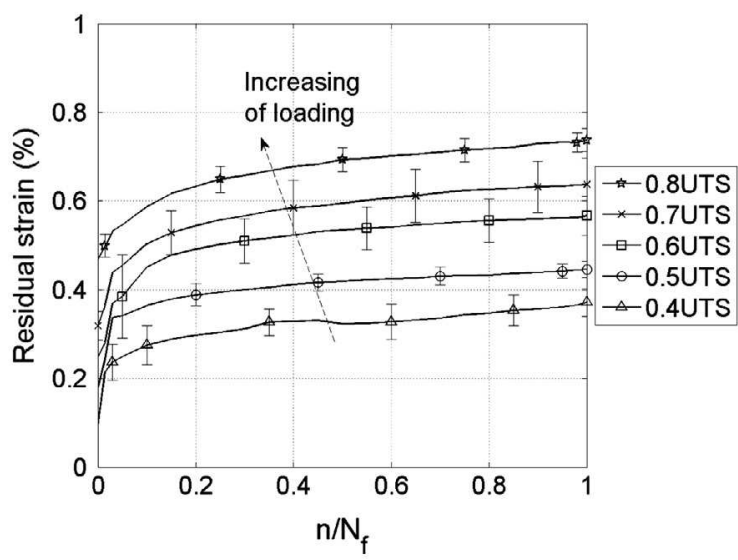

(c)

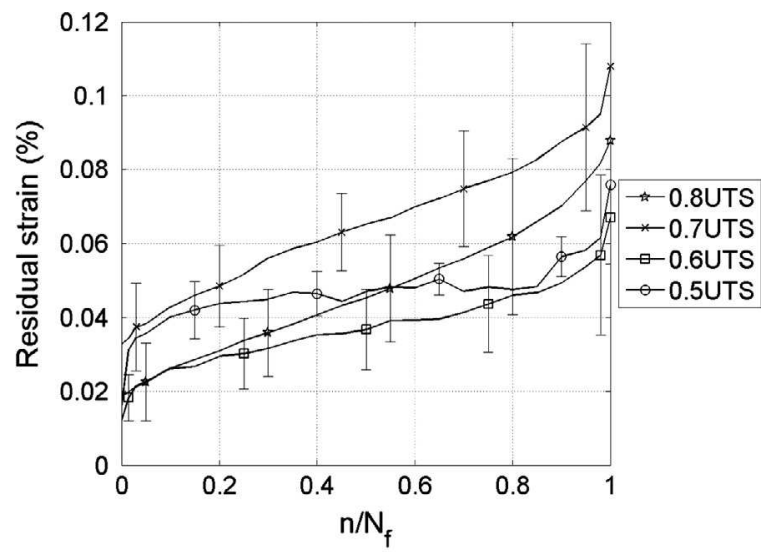

(b)

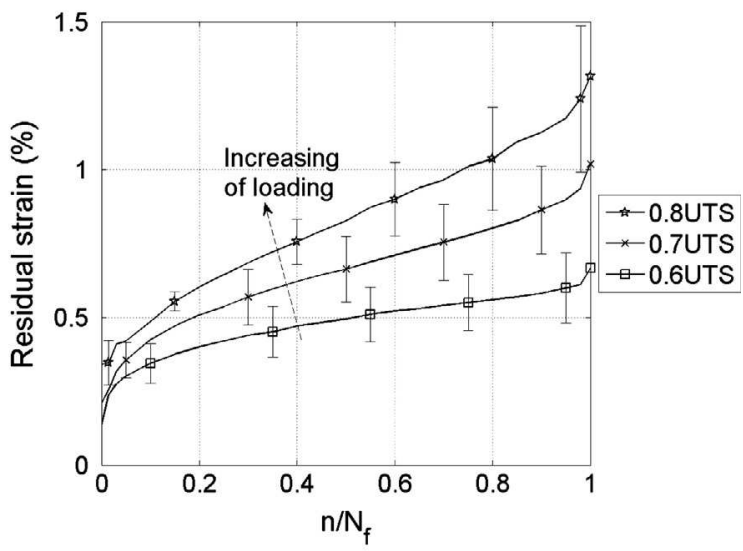

(d)

Fig. 5. Residual strains of (a) FE_0, (b) FE_90, (c) FE_090 and (d) FE_45 for loading levels from 0.4 to 0.8 UTS. 


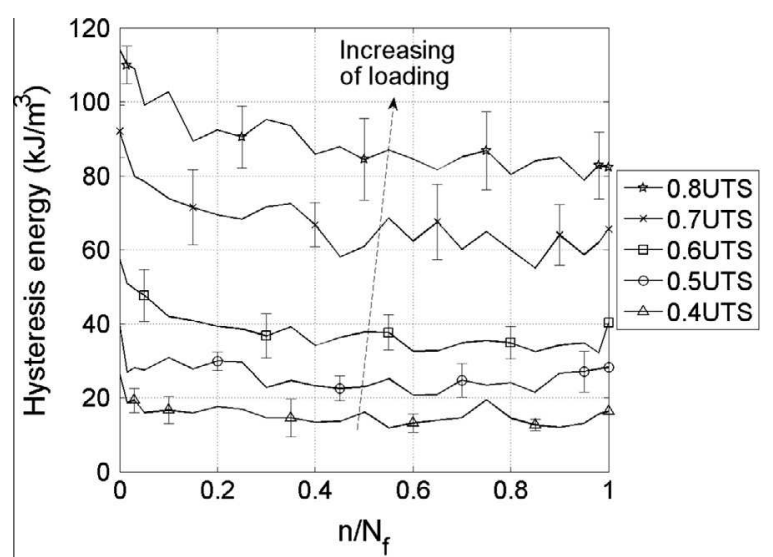

(a)

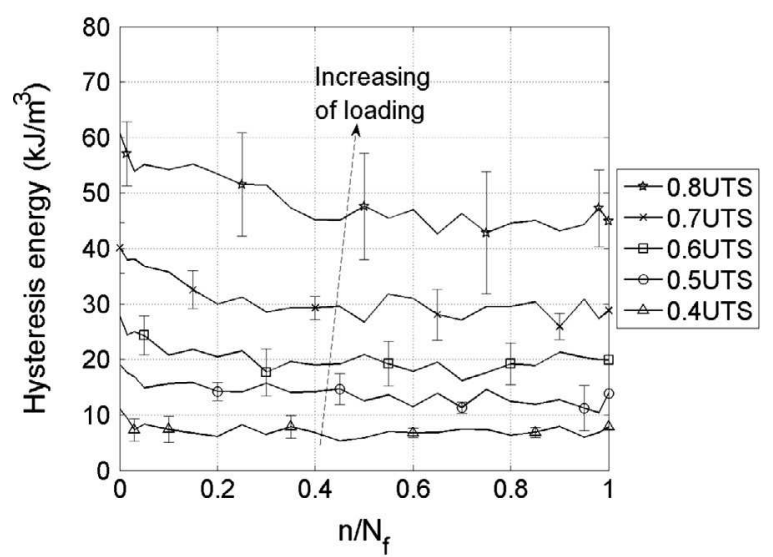

(c)

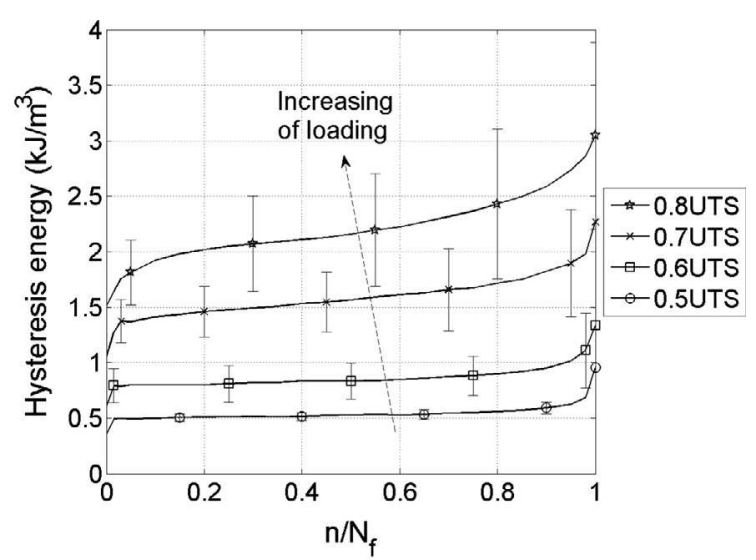

(b)

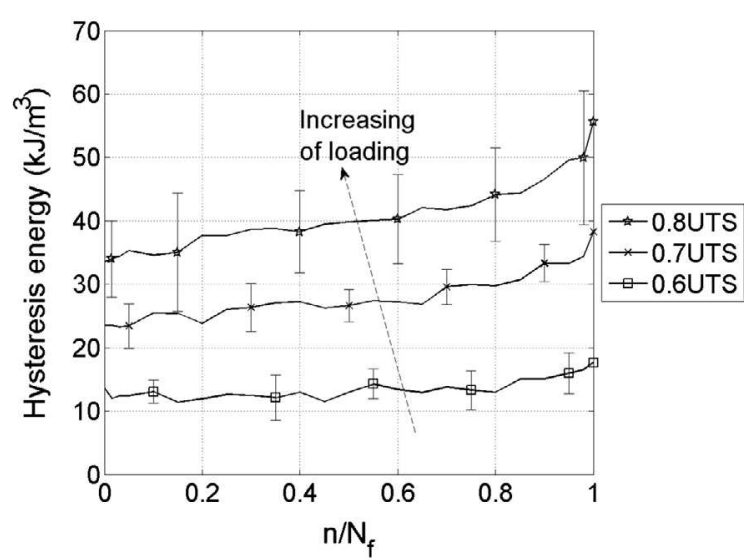

(d)

Fig. 6. Evolution of hysteresis energy for (a) FE_0, (b) FE_90, (c) FE_090, (d) FE_45, for loading levels from 0.4 to 0.8 UTS.

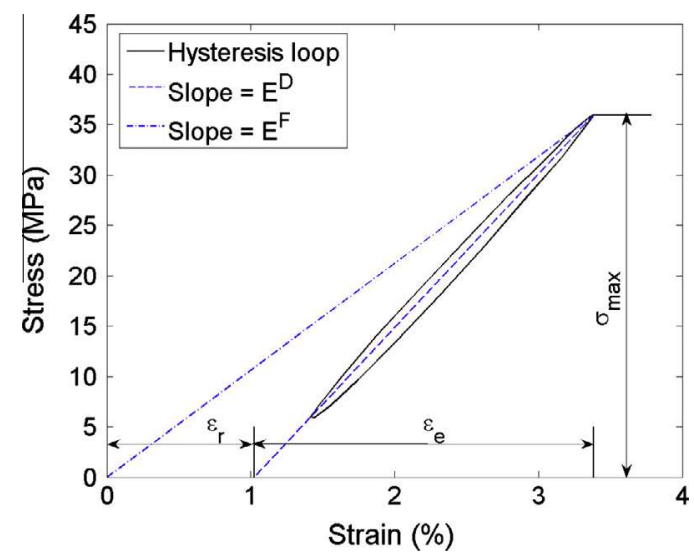

Fig. 7. Dynamic modulus and fatigue modulus from hysteresis loops under load controlled fatigue test.

accuracy of sensor, the inherent scattering of the material and the quality of the operating process. The strain evolution of matrix controlled laminates for the FE_90 and FE_45 samples presents three distinct stages. The last stage is a short unstable acceleration phase before failure. However, this step is not detected for FE_0 and FE_090 samples. Similar observations have been reported for glass/epoxy composites by Ellyin and Kujawski [23].

\subsection{Hysteresis energy}

The evolution of hysteresis energy, corresponding to the area enclosed within a loop (Fig. 4), is plotted in Fig. 6a-d for all types of specimens and loading levels as a function of the life ratio.

The higher the loading level, the more important the hysteresis energy, because the increment of the loop size. It can be noted that for FE_90 and FE_45 the energy increases with the life cycles for a given load level, as reported for conventional composite materials [17]. Similarly to permanent strain evolution (Fig. 5a-d), a three stages evolution can be considered. Nevertheless, the energy dissipation of FE_0 and FE_090 exhibits a decreasing trend with the life ratio. This typical behaviour is also in contrast with that of corresponding conventional glass/epoxy [24] and carbon/epoxy [25] systems. That difference in behaviour can be attributed to the influence of the flax reinforcements oriented in the direction of loading. This phenomenon will be discussed latter.

\subsection{Stiffness evolution}

The slope of the axis of the hysteresis loop (Fig. 7), corresponding to the dynamic modulus $\left(E^{D}\right)$, or secant modulus, may become more or less steep implying an increase (stiffening) or degradation of the modulus. Generally, internal damage development results in a loss of modulus [26,27].

The curves presented in Fig. 8a-d shows the evolution of the normalized dynamic modulus, that is the ratio of the cyclic dynamic modulus $\left(E^{D}\right)$ to the measured modulus during the first 


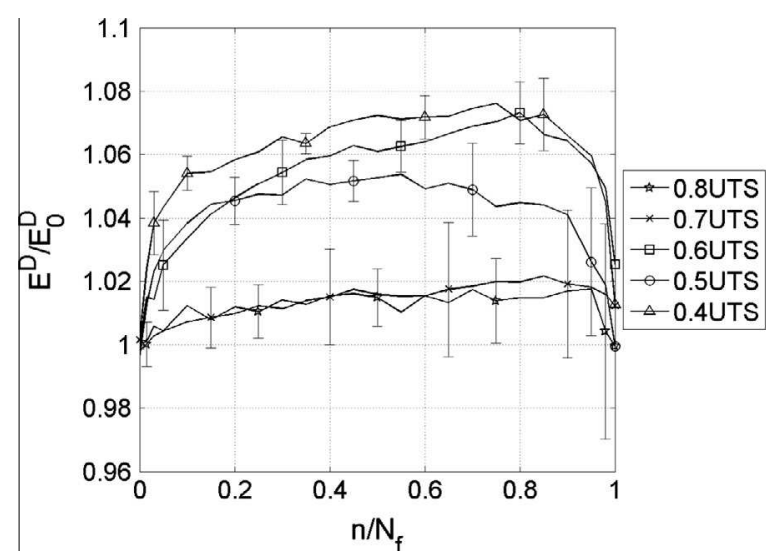

(a)

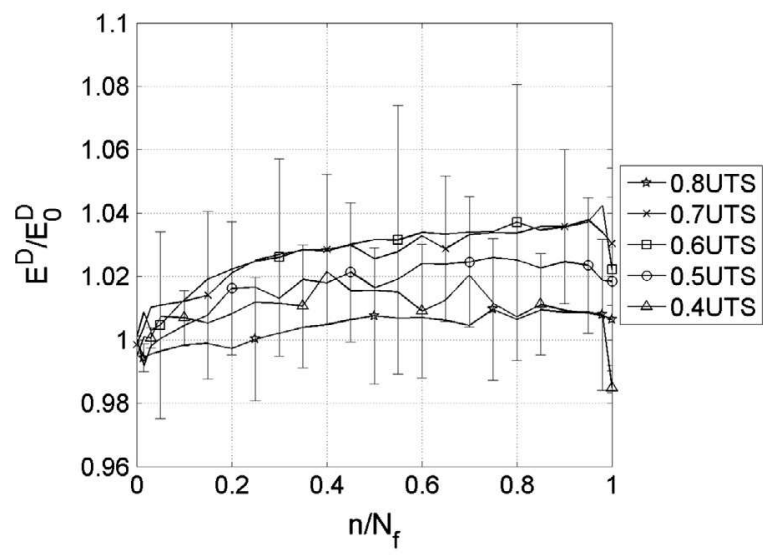

(c)

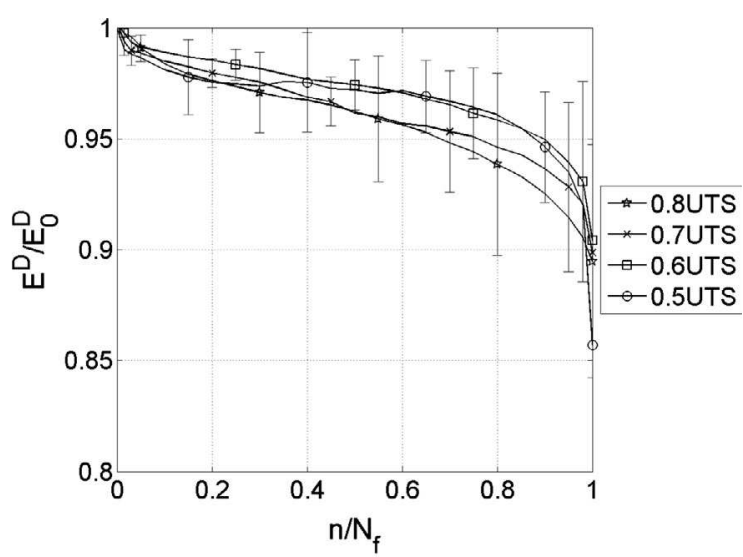

(b)

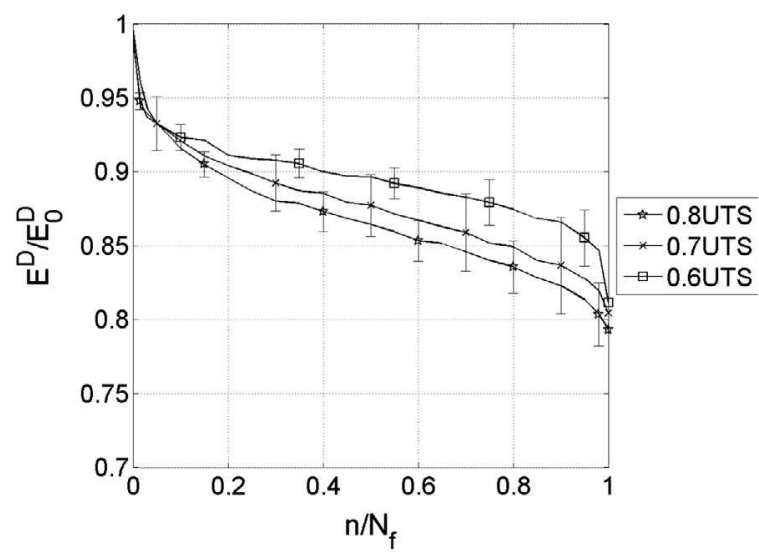

(d)

Fig. 8. Evolution of the normalized dynamic modulus for (a) FE_0, (b) FE_90, (c) FE_090 and (d) FE_45 for loading levels from 0.4 to 0.8 UTS.

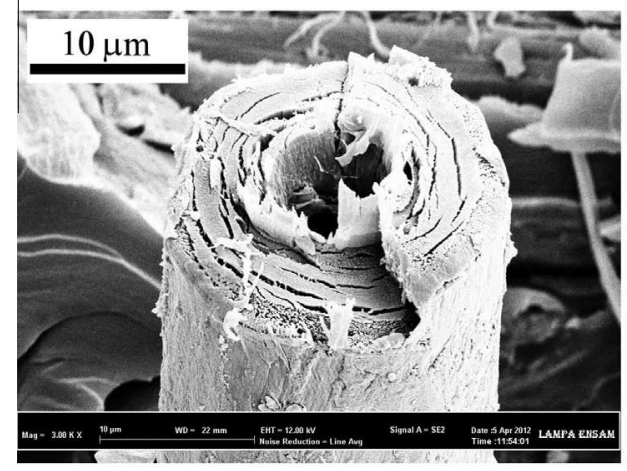

(a)

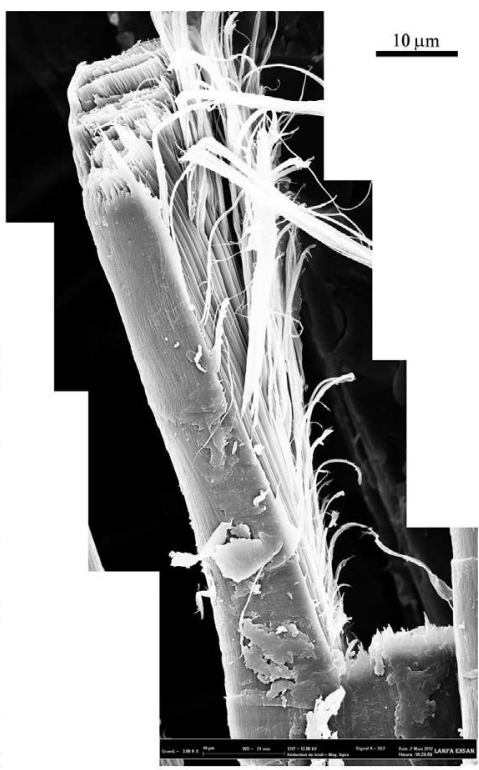

(b)

Fig. 9. SEM view of (a) the concentric structure of flax fibre with presence of lumen and (b) longitudinal view of broken fibre with pull-out of microfibrills. 


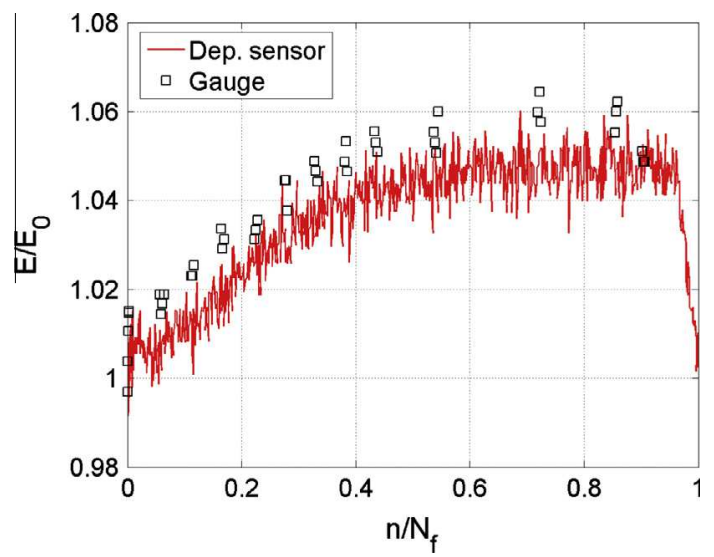

Fig. 10. Evolution of the normalized dynamic Young's modulus for FE_0 specimen loaded at 0.6 UTS. Strains calculated from the crosshead displacement and strain gauge.

cycle $\left(E_{0}^{D}\right)$. The stiffness of FE_90 and FE_45 specimens decreases in three stages similarly to the general behaviour of materials loaded in fatigue as described by Case and Reifsnider [28]. An initial stage with rapid stiffness reduction is followed by an intermediate step with a steady but slow decrease and a final acceleration before specimens failure. Conversely, for FE_0 and FE_090 specimens, the stiffness increased of around 1-8\% from the early loading cycles and then remained stable or slightly

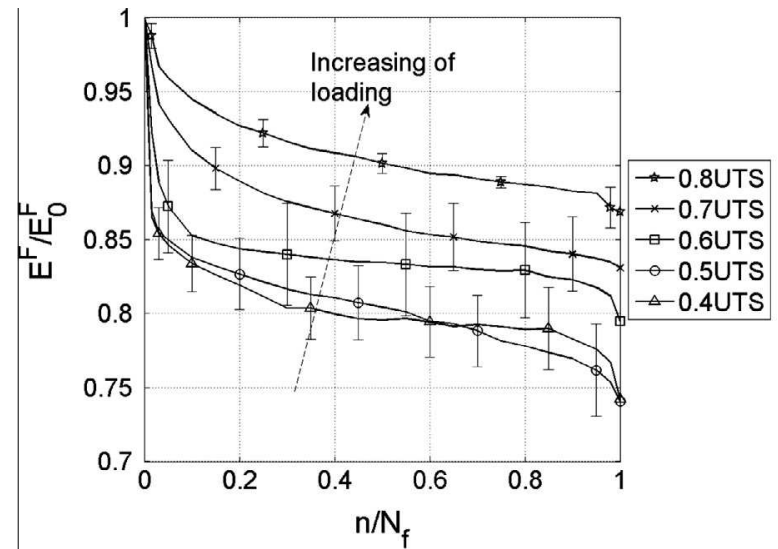

(a)

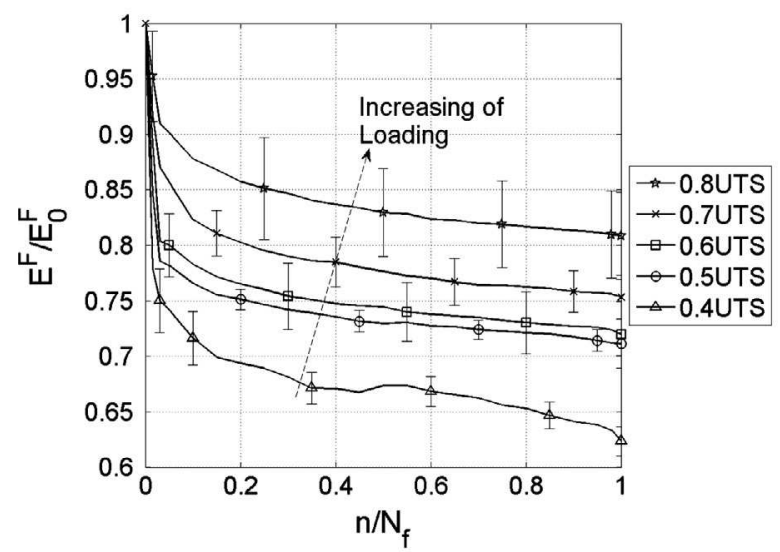

(c) increased until failure with rapid modulus drop (Fig. 8a and c). This latter observation points out a material stiffening phenomenon.

Similar stiffening effects have been reported by authors for some conventional composite materials due to the annealing of the polymer matrix [29] or the reorientation of the off-axis fibres [30]. However, it can be considered in this present case that the stiffening of natural fibre reinforced composite under cyclic loading, is intrinsically caused by the straightening of the microfibrills [17] inside fibres. Indeed, the elementary flax fibre has an heterogeneous structure consisting of a very thin primary cell wall surrounding a thicker secondary cell wall, concentrically arranged around a lumen (Fig. 9a). The cellulosic microfibrills contained in the second wall are held together by a polysaccharide based matrix (pectin, lignin, hemicellulose), and represent the principal component of the fibre (60-75\% in weight) with a high longitudinal modulus of approximately $134 \mathrm{GPa}$ [18]. A longitudinally broken flax fibre, shown in Fig. 9b, confirms its fibrous structure. When fibres are axially loaded, the microfibrills naturally aligned with an angle of around $10^{\circ}$ with respect to the fibre axis $[6,18]$, tend to reorient themselves after each cycle. This hypothesis results in a decrease of microfibrills angle and an incremental increase of fibre stiffness along the loading direction as confirmed by the stiffening tendency of dynamic modulus curves of FE_0 and FE_090, containing a significant fraction of $0^{\circ}$ oriented plies.

Nevertheless, the increase of stiffness reached $2-8 \%$ for FE_0 and $1-4 \%$ for FE_090, depending on the loading level (Fig. 8a and c). The difference of the stiffening degree for the two lay-ups can be explained by the more important presence of $0^{\circ}$ oriented fibres in FE_0 composites. Regarding FE_090 specimens, the combination

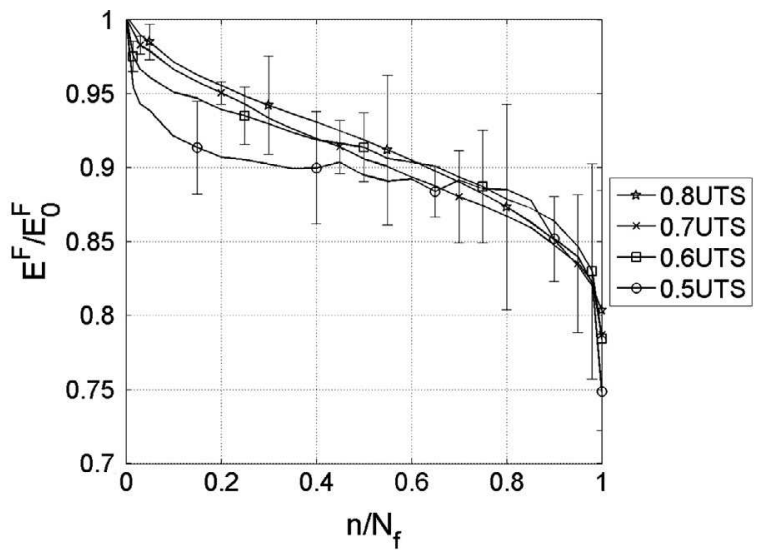

(b)

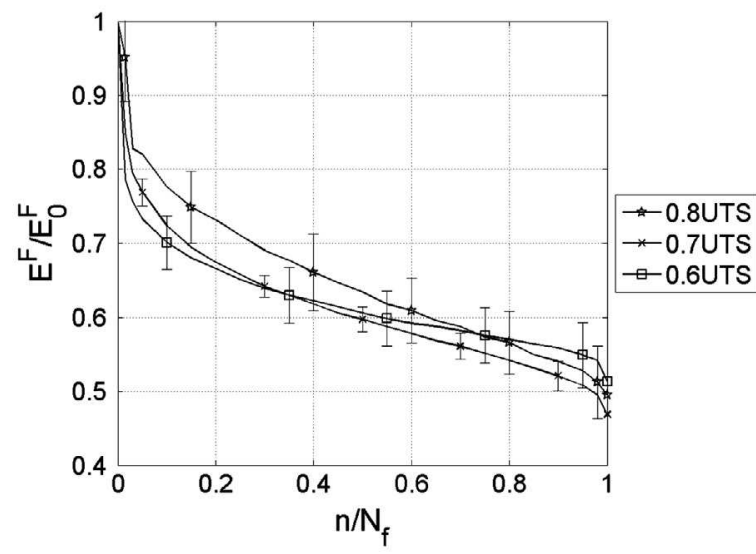

(d)

Fig. 11. Evolution of the fatigue modulus for (a) FE_0, (b) FE_90, (c) FE_090 and (d) FE_45 for loading levels from 0.4 to 0.8 UTS. 


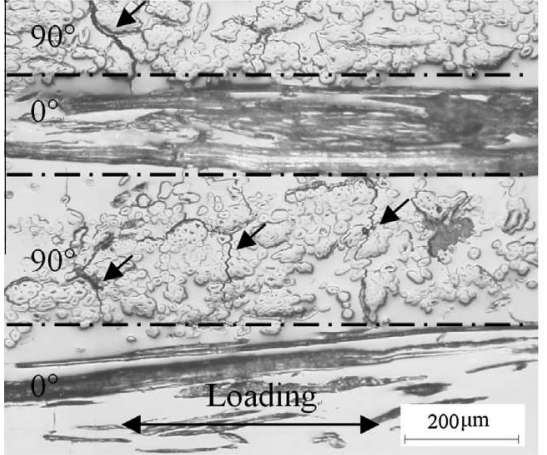

(a)

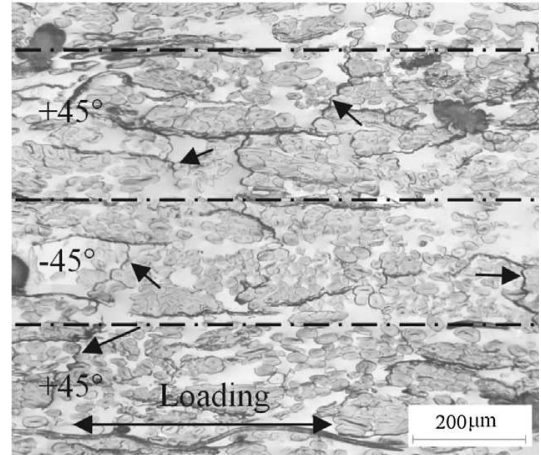

(b)

Fig. 12. Typical micrographs of (a) FE_090 and (b) FE_45 edges. Arrows pointing on the transverse cracks.

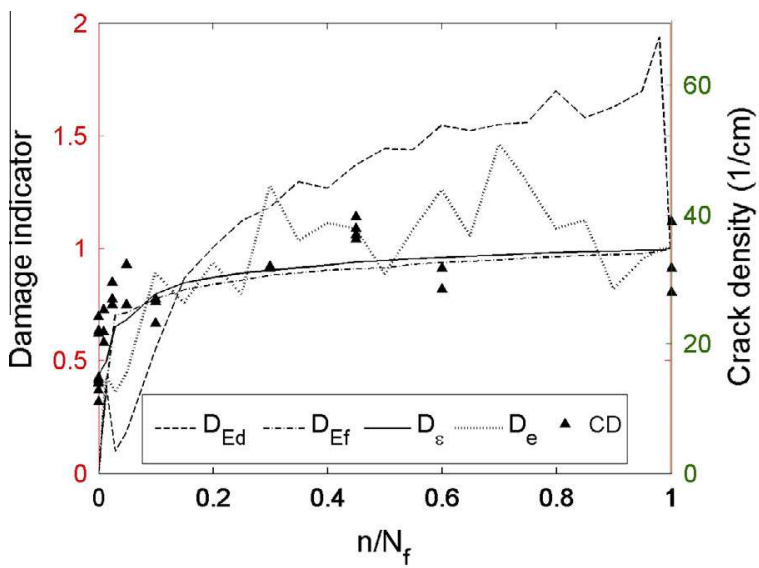

(a)

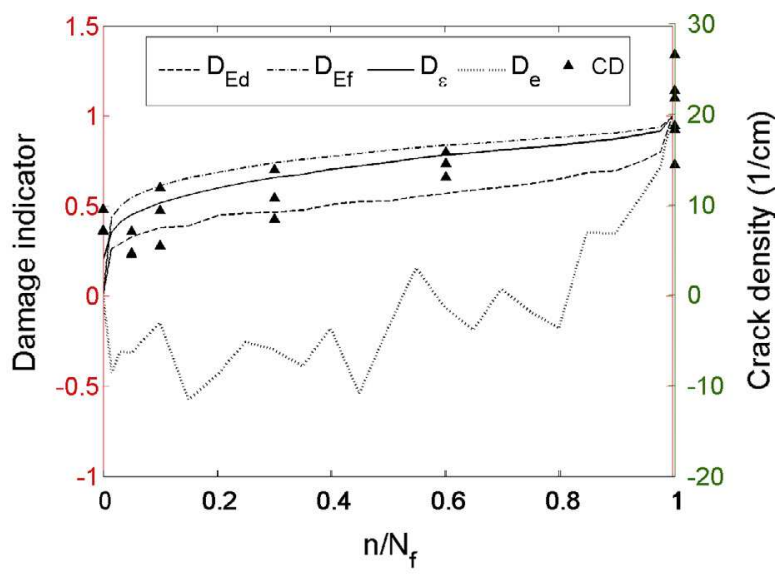

(b)

Fig. 13. Crack density and damage evolution for (a) FE_090 and (b) FE_45 as a function of the life ratio.

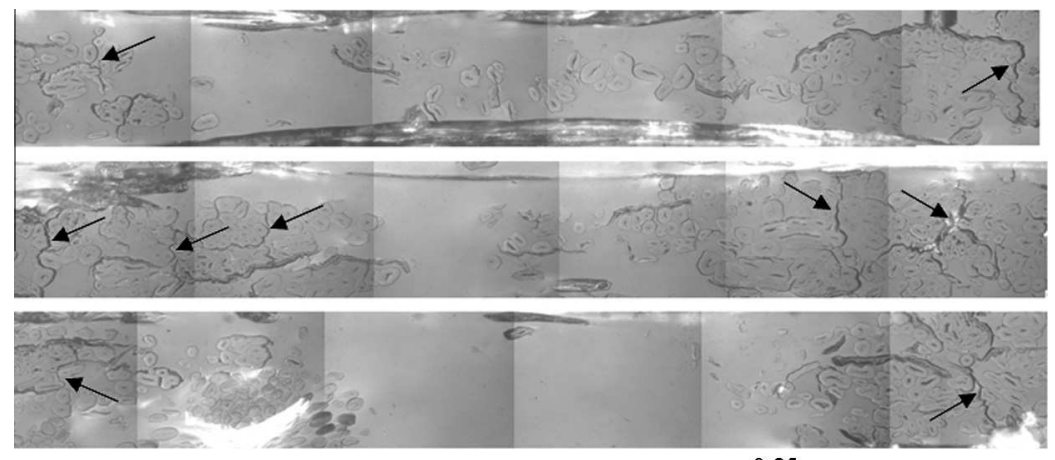

$0.25 \mathrm{~mm}$

Fig. 14. Micrographs of 3 different locations on one FE_090 specimen's edge. Arrows point the cracks. No crack observed in rich resin regions.

of modulus increase for $0^{\circ}$ layers and loss for $90^{\circ}$ layers (Fig. $8 \mathrm{~b}$ ) reduced overall the laminate stiffening.

In order to assess the accuracy of the strain calculated from crosshead displacement, this measurement has been compared to strain data recorded from a strain gauge glued over the midpoint of a FE_0 specimen tested at 0.6 UTS (Fig. 10). It can be noticed that the same trend is given by both methods, even though the displacement sensor tends to slightly under estimate the increase in modulus.
Hwang and Han [31] have defined the fatigue modulus $\left(E^{F}\right)$ as the ratio of the maximum cyclic stress $\left(\sigma_{\max }\right)$ to strain $\left(\varepsilon_{\max }\right)$ (Eq. (2)). The latter is the sum of residual permanent strain $\left(\varepsilon_{r}\right)$ and elastic strain $\left(\varepsilon_{e}\right)$ schematized in Fig. 7. Thus, the fatigue modulus takes into account the strain shifting accumulation $\left(\varepsilon_{r}\right)$ and the loop axis rotation $\left(E^{D}\right)$.

$E^{F}=\sigma_{\max } / \varepsilon_{\max }=\sigma_{\max } /\left(\varepsilon_{r}+\varepsilon_{e}\right)$ 


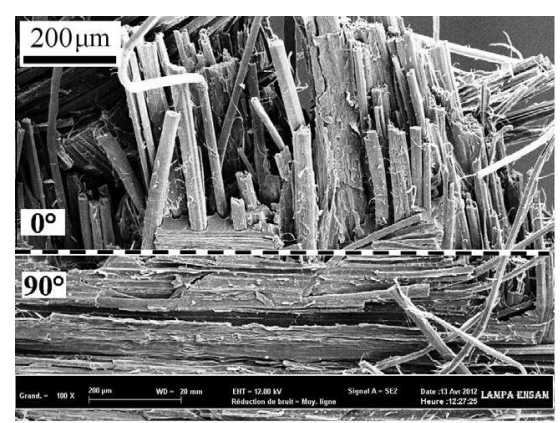

(a)

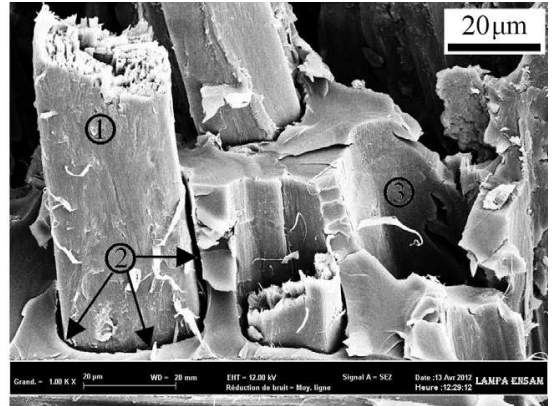

(b)

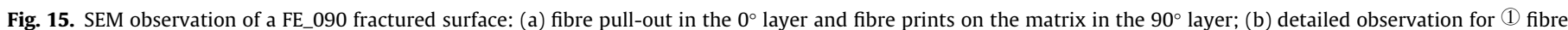
pull-out, (2) fibre/matrix debonding and (3) fibre print left on the matrix after fibre pull out.

Fatigue modulus $\left(E^{F}\right)$ versus life ratio have been plotted in Fig. 11a-d. For all specimen types, $E^{F}$ decreased with the life ratio. The maximum loss was of $25 \%$ for FE_0 and FE_90, but reached 38$55 \%$ for FE_090 and FE_45 respectively. On the other hand, the decrease of modulus depended on the loading level for specimens with fibre control behaviour (FE_0 and FE_090). As the load was increased, the loss of modulus decreased (Fig. 11a and c). However, no correlation was shown between modulus and loading condition for FE_90 and FE_45 specimens whose behaviour is more sensitive to the matrix influence (Fig. 11b and d).

The effects of creep and elastic compliance are superimposed in fatigue modulus measurement. Therefore, Petermann and Schulte [30] suggested that the study of creep strain and elastic compliance separately was more reasonable. Material health is currently assessed in literature [31-33] by the damage indicator $(D)$ given by Eq. (3). However, the use of $E^{D}$ may lead to negative value of $D$ for FE_0 and FE_090, suggesting a more healthy material, whereas failure occurs for stress levels lower than the UTS. Therefore, $E^{F}$ seems to be more adequate for the damage assessment of flax reinforced composites.

$D=1-E / E_{0}$

It is remarkable that, for matrix controlled laminates, the profile of the properties evolution $\left(\varepsilon_{r}\right.$, hysteresis, $\left.E^{F}, E^{D}\right)$ presented the same monotonic, three stages form, with similar occupied life ratio, while flax fibre controlled laminate showed two or three stages evolutions depending on the loading levels and the parameters studied.

\subsection{Damage evolution}

The crack density (CD) is usually chosen to assess damage in off-axe layers of multi-directional laminates. Therefore, cracks in $90^{\circ}$ and $\pm 45^{\circ}$ layers of respectively FE_090 and FE_45 specimens have been observed for crack development monitoring.

Based on the micrographs from the edges (Fig. 12a and b), the evolution of the CD for FE_090 and FE_45 specimens tested at 0.6 UTS was plotted in Fig. 13a and b. Specimens were tested for a certain number of cycles. The intervals were small for low numbers of cycles then increased for important life cycles. On average, measurements represented by points, in three different locations on the edge were performed for each specimen. For FE_090, the CD increased rapidly until $0.05 N_{f}$, then remained relatively constant until failure with a CD of $33 \pm 6 / \mathrm{cm}$. As to FE_45, the CD measured for samples tested after one fatigue cycle was $8 / \mathrm{cm}$, and increased fast from the origin to $0.1 N_{f}$. Thereafter, cracking density increased more slowly with a final acceleration phase appearing before fracture for $C D=20 \pm 4 / \mathrm{cm}$. These $C D$ evolutions kinematics for both FE_090 and FE_45 samples correlate well with the residual strain profile plotted in Fig. $5 \mathrm{c}$ and $\mathrm{d}$.

The kinetics of damage has been evaluated by four additional indicators $D_{e}, D_{\varepsilon}, D_{E d}$ and $D_{E f}$ based on the corresponding average experimental data of the hysteresis energy $(e)$, residual strain $\left(\varepsilon_{r}\right)$, dynamic modulus $\left(E^{D}\right)$ and fatigue modulus $\left(E^{F}\right)$ respectively, and superimposed in Fig. 13a and b. The indicators given by Eq. (4) to Eq. (7), are equal to 0 for intact and 1 for failure situation [34,35]. Subscripts $0, i$ and 1 refer respectively to the intact, current and final life ratio.

$$
\begin{aligned}
& D_{e}=\left(e_{i}-e_{0}\right) /\left(e_{1}-e_{0}\right) \\
& D_{\varepsilon}=\left(\varepsilon_{r i}-\varepsilon_{r 0}\right) /\left(\varepsilon_{r 1}-\varepsilon_{r 0}\right) \\
& D_{E d}=\left(E_{0}^{D}-E_{i}^{D}\right) /\left(E_{0}^{D}-E_{1}^{D}\right) \\
& D_{E f}=\left(E_{0}^{F}-E_{i}^{F}\right) /\left(E_{0}^{F}-E_{1}^{F}\right)
\end{aligned}
$$

$D_{\varepsilon}$ and $D_{E f}$ fit satisfactorily the CD evolution for FE_090, whereas $D_{e}$ and $D_{E d}$ overestimate excessively the CD increase for FE_090 and give damage value superior to unity during an important life ratio before failure (Fig. 13a). The CD is well correlated by $D_{\varepsilon}, D_{E d}$ and $D_{E f}$ for FE_45 (Fig. 13b). $D_{e}$ does not match with the crack growth.

It is remarkable that almost all cracks observed were located in fibre/matrix interfaces, in fibre rich zones (Fig. 14). Thus, nearly no transverse crack was found in resin rich region. This phenomena can be explained by the weak transverse strength of flax/epoxy (FE_90) at $26 \mathrm{MPa}$ compared to the tensile strength of pure resin at about 64-84 MPa [36], that suggests easier damage creation in composites. Baley et al. [37] has also shown that the crack growth along fibre/matrix interfaces was the primary damage mechanism in flax/polyester under transverse tensile load. SEM images of the fractured surface of a FE_090 specimens (Fig. 15a and b) shows that massive fibres pull-outs in the $0^{\circ}$ layer and fibres prints left on the matrix in the $90^{\circ}$ layer. This observation highlighted a poor fibre/matrix bonding, suggesting there is still an important potential to increase the performance of flax reinforced composites by improving the quality of interface adhesion.

\section{Conclusion}

Experimental investigations were conducted on flax/epoxy specimens with $[0]_{12},[90]_{12},[ \pm 45]_{3 s}$ and $[0 / 90]_{3 s}$ stacking sequences under tensile-tensile fatigue loading. Resulting S-N curves have shown a good fit with the linear Wöhler's model. Composites having higher static strength exhibited better fatigue resistance. However, the normalized stress versus number of 
cycles of FE_45 specimens presented the highest endurance limit of 0.5 UTS. The probabilized S-N curves confirmed that a raise of the material survival probability reduced significantly the expected life.

For FE_90 and FE_45, the evolution of the permanent strain, hysteresis energy, dynamic and fatigue modulus was in accordance with that of conventional glass, carbon fibre reinforced polymers material. The hysteresis energy tended to decrease while the dynamic modulus increased of $2-8 \%$ for FE_0 and $1-4 \%$ for FE_090 with loading cycles. This strengthening is thought to be related to the realignment of flax fibres microfibrils in $0^{\circ}$ layers loaded along fibre axis. The measured fatigue modulus exhibited loss of $10-55 \%$, depending on the loading level and the staking sequence.

Damage indicators based on residual strain and fatigue modulus were well correlated with crack density evolution for FE_090, while the indicator based on hysteresis energy did not match the CD growth for FE_45. Transverse cracking was found mainly around the fibre/matrix interface and a large number of fibres pull-out and fibres prints were observed on the fractured surface, suggesting that the improvement of interfacial adhesion was an interesting issue for the improvement of the performance of natural fibre based composites.

\section{Acknowledgements}

The financial support of the Faber fund from the Bourgogne Region, France is gratefully acknowledged.

\section{References}

[1] Kompella MK, Lambros J. Micromechanical characterization of cellulose fibers. Polym Test 2002:21:523-30.

[2] Pickering KL, Beckermann GW, Alam SN, Foreman NJ. Optimising industrial hemp fibre for composites. Compos: Part A 2007;38:461-8.

[3] Placet V. Characterization of the thermo-mechanical behaviour of Hemp fibres intended for the manufacturing of high performance composites. Compos: Part A. 2009;40:1111-8.

[4] Silva FA, Chawla N, Filho RDT. An experimental investigation of the fatigue behavior of sisal fibers. Mater Sci Eng A 2009;516:90-5.

[5] Bos HL, Van Den Oever MJA, Peters OCJJ. Tensile and compressive properties of flax fibres for natural fibre reinforced composites. J Mater Sci 2002:37:1683-92.

[6] Bos HL, Donald AM. In situ ESEM study of the deformation of elementary flax fibres. J Mater Sci 1999:221-74.

[7] Summerscales J, Dissanayake N, Virk AS, Hall W. A review of bast fibres and their composites. Part 1 - fibres as reinforcements. Compos Part A: Appl Sci Manuf 2010;41:1329-35.

[8] John M, Anandjiwala RD. Recent developments in chemical modification and characterization of natural fiber-reinforced composites. Polym Compos 2008:187-207.

[9] Kalia S, Kaith BS, Kaur I. Pretreatments of natural fibers and their application as reinforcing material in polymer composites - a review. Polym Eng Sci 2009;49:1253-72.
[10] Bodros E, Pillin I, Montrelay N, Baley C. Could biopolymers reinforced by randomly scattered flax fibre be used in structural applications? Compos Sci Technol 2007;67:462-70.

[11] Assarar M, Scida M, Mahi AE, Poilâne C, Ayad R. Influence of water ageing on mechanical properties and damage events of two reinforced composite materials: flax fibres and glass fibres. Mater Des 2011;32:788-95.

[12] Gning PB, Liang S, Guillaumat L, Pui WJ. Influence of process and test parameters on the mechanical properties of flax/epoxy composites using response surface methodology. J Mater Sci 2011;46:6801-11.

[13] Meredith J, Ebsworth R, Coles SR, Wood BM, Kirwan K. Natural fibre composite energy absorption structures. Compos Sci Technol 2012;72:211-7.

[14] Tong Y, Isaac DH. Impact and fatigue behaviour of hemp fibre composites. Compos Sci Technol 2007;67:3300-7.

[15] Towo AN, Ansell MP. Fatigue evaluation and dynamic mechanical thermal analysis of sisal fibre-thermosetting resin composites. Compos Sci Technol 2008;68:925-32.

[16] Shah DU, Schubel PJ, Clifford MJ, Licence P. Fatigue life evaluation of aligned plant fibre composites through S-N curves and constant-life diagrams. Compos Sci Technol 2013;74:139-49.

[17] Liang S, Gning PB, Guillaumat L. A comparative study of fatigue behaviour of flax/epoxy and glass/epoxy composites. Compos Sci Technol 2012;72:535-43.

[18] Baley C. Analysis of the flax fibres tensile behaviour and analysis of the tensile stiffness increase. Compos: Part A 2002;33:939-94.

[19] ASTM D 3171-99. Standard test methods for constituent content of comp mater.

[20] ISO 13003, Fibre-reinforced plastic - Determination of fatigue properties under cyclic loading conditions, 2003.

[21] A 03-405, Traitement statistique des données. 1991.

[22] De Monte M, Moosbrugger E, Quaresimin M. Influence of temperature and thickness on the off-axis behaviour of short glass fibre reinforced polyamide 6.6 - cyclic loading. Compos: Part A 2010;41:1368-79.

[23] Ellyin F, Kujawski D. Tensile and fatigue behaviour of glass fibre/epoxy laminates. Construction Build Mater 1995;9(6):425-30.

[24] Naderi M, Khonsari MM. On the role of damage energy in the fatigue degradation characterization of a composite laminate. Compos: Part B 2013;45:528-37.

[25] Barron V, Buggy M, McKenna NH. Frequency effects on the fatigue behaviour on carbon fibre reinforced polymer laminates. J Mater Sci 2001;36:1755-61.

[26] Talreja R. Fatigue of composite materials. Lancaster (PA): Technomic Publishing Company Inc.; 1987. p. 177.

[27] Yang JN, Jones DL, Yang SH, Meskini A. A stiffness degradation model for graphite/epoxy laminates. J Compos Mater 1990;24:753-70.

[28] Case SW, Reifsnider KL. Fatigue of Composite Materials. Compr Struct Integrity 2003:405-41 [Chapter 4.16].

[29] Greco A, Musardo C, Maffezzoli A. Flexural creep behaviour of PP matrix woven composite. Compos Sci Technol 2007;67:1148-58.

[30] Petermann J, Schulte K. The effects of creep and fatigue stress ratio on the longterm behaviour of angle-ply CFRP. Compos Struct 2002;57:205-10.

[31] Hwang W, Han KS. Fatigue of composites - fatigue modulus concept and life prediction. J Compos Mater 1986;20:154-65.

[32] Plumtree A, Melo M, Dahl J. Damage evolution in a [ \pm 45$] 2 S$ CFRP laminate under block loading conditions. Int J Fatigue 2010;32:139-45.

[33] Lin Y. On fatigue damage accumulation and material degradation in composite materials. Compos Sci Technol 1989;36:339-50.

[34] Post NL, Case SW, Lesko JJ. Modeling the variable amplitude fatigue of composite materials: a review and evaluation of the state of the art for spectrum loading. Int J Fatigue 2008;30:2064-86.

[35] Kam TY, Tsai SY, Chu KH. Fatigue reliability analysis of composite laminates under spectrum stress. Int J Solids Struct 1997;34:1441-61.

[36] Factsheet of SICOMIN, SR 8200 Systèmes époxydes de stratification. Version du 9 Janvier 2002

[37] Baley C, Perrot Y, Busnel F, Guezenoc H, Davies P. Transverse tensile behaviour of unidirectional plies reinforced with flax fibres. Mater Lett 2006;60:2984-7. 